\title{
Effectiveness of Ice Compress Application upon the Level of Pain among Patients with Chest Drainage
}

Sandhya $\mathrm{R}^{1}$, Sujitha Jebarose ${ }^{2}$

\begin{abstract}
Background: Chest drain tube poses a greater intensity of pain in a patient, especially during its removal. It is necessary for a nurse to recognize the severity of pain and treat it accordingly with nonpharmacological treatments to prevent side effects and ease comfort.

Objective: To assess the efficacy of ice pack application by differentiating the before and after assessment of severity of pain among the control and the ice pack group of patients with chest tubes.

Materials and methods: The present study was conducted using experimental research design. A total of 60 patients with chest tubes were selected by systematic sampling method, assigning 30 patients to control group and ice pack group after ruling out their inclusion criteria. Data were collected using a demographic pro forma, clinical pro forma, Numerical rating pain scale, and Mc Gill Pain Questionnaire.

Results: The results revealed that the scores of posttest severity pain in the control group by numerical rating scale $[\mathrm{mean}(\mathrm{M})=7.06$, standard deviation $(S D)=0.77$ ] and $M c$ Gill Pain questionnaire $(M=2, S D=0.51)$ and in the ice pack group by numerical rating scale $(M=1.8, S D=1.11)$ and $M c$ Gill Pain questionnaire $(M=0.1, S D=0)$ showed a statistically significant difference for " $t$ " value of 35.39 (NRS) and 31.67 (Mc Gill Pain questionnaire) at $p$ value $<0.001$ which may be attributed to the ice pack application.

Conclusion: The ice pack application has a remarkable effect on the severity of pain during chest tube removal.

Keywords: Chest tubes, Ice pack application, Mc Gill pain questionnaire, Pain.

Pondicherry Journal of Nursing (2020): 10.5005/jp-journals-10084-12153
\end{abstract}

\section{INTRODUCTION}

Cardiovascular disorders are expeditiously increasing owing to physiological and psychological constraints and unhealthy lifestyles. Many patients undergo cardiothoracic surgery. Following a cardiothoracic surgery, chest drain tubes are inserted into the thoracic cavity. These drain tubes act by the mechanism of one-way valve to drain fluid or air and prevent backflow from the pleural and the thoracic cavity. ${ }^{1}$ The chest tubes are taken off once the fluid reduces or stops and with an achievable hemodynamic parameters. Removal of chest drain tube is frightening and painful and described as a worst experience. ${ }^{2,3}$

Short-term analgesics, especially paracetomol, are given to relieve pain. But still the pain control is debatable and added up are the several side effects. ${ }^{4}$ The need for pain relief is an important concern today in the society. While pain is currently the urgent concern of world health, global healthcare organizations focus on pain relief by focusing on alternative and complimentary therapies for pain relief. Hence, it is better to add up an alternative therapy along with a medical treatment to maximize the pain control. Physiological therapy to decrease the severity of pain, including ice application, has been suggested earlier. Ice therapy has a significant short-term analgesic effect for many disorders causing pain as a primary symptom. Cryo/ice therapy attenuates pain by the antinociceptive technique, reducing the painful nerve conductions by acting on the gate control system. ${ }^{5}$

Ice numbs the sensory pain nerve terminals, decreasing the conduction of pain. Peripheral application of ice results in vasoconstriction; decreases the blood flow to that particular region; minimizes the production of histamine, serotonin, and bradykinin; and diminishes the severity of inflammation, pain, and edema. However, the insertion of chest tube causes pain due to damaged
1,2Faculty of Nursing, Dr MGR Educational and Research Institute, Chennai, Tamil Nadu, India

Corresponding Author: Sandhya R, Faculty of Nursing, Dr MGR Educational and Research Institute, Chennai, Tamil Nadu, India, Phone: +91 7448776786, e-mail: sandhiramachandran@gmail.com

How to cite this article: Sandhya R, Jebarose S. Effectiveness of Ice Compress Application upon the Level of Pain among Patients with Chest Drainage. Pon J Nurs 2020;13(1):7-10.

Source of support: Nil

Conflict of interest: None

intercostal nerves at the incision site and irritation of pleura during catheter placement and removal. ${ }^{6,7}$

Mazolum et al. conducted a single blinded crossover clinical trial to assess the pain level after use of ice bag on the removal of chest tube after cardiac surgery in 51 patients. Patients were grouped into the following three groups: ice bag, placebo, and control. Pain level was measured with visual analog scale (VAS). The pain levels were significantly less in the ice bag group compared to the other two groups. ${ }^{8}$

Hence, it is necessary that the nurses evaluate pain severity and alleviate the patient from pain by the use of different clinical assessment tools and best available nursing skills. Nonpharmacological therapies always have its own merits with less side effects which the nurses by their standing orders can implement to the patients to lessen the severity of pain. ${ }^{9}$

\section{Statement of the Problem}

A study to evaluate the efficacy of ice pack on the severity of pain among patients with chest tubes in selected hospitals, Chennai.

() The Author(s). 2020 Open Access This article is distributed under the terms of the Creative Commons Attribution 4.0 International License (https://creativecommons. org/licenses/by-nc/4.0/), which permits unrestricted use, distribution, and non-commercial reproduction in any medium, provided you give appropriate credit to the original author(s) and the source, provide a link to the Creative Commons license, and indicate if changes were made. The Creative Commons Public Domain Dedication waiver (http://creativecommons.org/publicdomain/zero/1.0/) applies to the data made available in this article, unless otherwise stated. 


\section{Objectives}

To evaluate the efficacy of ice pack by differentiating before and after assessment of severity of pain among the control and the ice pack group of patients with chest tubes.

\section{Materials and Methods}

The present study was conducted using experimental research design. A total of 60 patients with chest tubes were selected by systematic sampling method, assigning 30 patients to the control group and 30 patients to the ice pack group after ruling out their inclusion criteria, which are medical and surgical cardiothoracic patients with chest tubes aged between 20 years and 60 years. The exclusion criteria were patients with low GCS and those on sedation, anesthesia, and mechanical ventilation. Data were collected using a demographic pro forma, Clinical pro forma, Numerical rating pain scale, and Mc Gill Pain Questionnaire. Ethical clearance was obtained, the purpose of this study was explained, consent was obtained, and confidentiality was assured to the study participants.

Demographic variables, clinical variables, and the baseline pain level were collected as a pretest among the control and the ice pack groups. Ice pack was placed around the chest tubes for 10 minutes with 10 minute lapse for 1 hour to the study group. The severity of pain was assessed before the chest tube removal, at once after the chest tube removal, and 15 minutes after the chest tube removal using Numerical rating pain scale and Mc Gill Pain Questionnaire for the control and the ice pack group of patients.

\section{Results}

Demographic data reveal that most of the patients $(40 \%$ and $66.67 \%)$ were between 41 years and 60 years and were males $(53 \%$ and $86 \%$ ) residing in urban region (63.34\% and $66.67 \%)$. Many of them were nonvegetarians ( $70 \%$ and $90 \%)$, had no family history of cardiothoracic disorders (53.34\% and 66.67\%), and were moderate workers (93\% and $76 \%$ ) in the control and the ice pack groups, respectively.

Clinical data show that greater number of patients $(80 \%$ and 73.34\%) had cardiac surgery, with chest tube in place for 1-3 days (90\% and $83.34 \%$ ): both anterior and pleural drain (50\% and $73 \%$ ), most of with pleural drain alone (33\% and $20 \%$ ), and anterior drains alone (16\% and 6\%). Majority of the patients ( $96.67 \%$ and $90 \%)$ had no previous experience of chest tubes and had increased severity of pain (63.34\% and $63.34 \%)$ during chest physiotherapy. Most of them had comorbid illness ( $60 \%$ and $56.67 \%$ ) in the control and the ice pack groups, respectively.

Analysis between posttest scores of pain in the control group by numerical rating scale [Mean $(M)=7.06$, standard deviation
$(S D)=0.77]$ and $M c$ Gill Pain questionnaire $(M=2, S D=0.51)$ and in the ice pack group by numerical rating scale $(M=1.8, S D=$ 1.11) and $M c$ Gill Pain questionnaire $(M=0.1, S D=0)$ showed a statistically significant difference of 35.39 (NRS) and 31.67 (Mc Gill Pain questionnaire) for " $t$ " value at $p$ value $<0.001$ which may be attributed to the ice pack application.

It could be inferred from the table that there was no significant association between selected demographic variables, namely, age, gender, nature of work, type of diet, and the severity pain. But there is a significant association between history of smoking and alcoholism and the severity of pain in the ice pack group.

It could be inferred that there was no significant association between selected clinical variables, namely, type and number of chest drain, physical activity, ambulation with chest tubes, and the severity of pain. But there is a significant association between those who had undergone cardiac surgeries and the severity of pain in ice pack group of patients (Tables 1 to 3 ).

\section{Discussion}

\section{Demographic Variables}

Demographic data reveal that most of the patients were between 41 years and 60 years ( $40 \%$ and $66.67 \%)$, were males $(53 \%$ and $86 \%)$, residing in urban region $(63.34 \%$ and $66.67 \%)$, most of them were nonvegetarians ( $70 \%$ and $90 \%)$, had no family history of cardiothoracic disorders (53.34\% and $66.67 \%)$, and were moderate workers (93\% and $76 \%$ ) in the control and the ice pack group, respectively.

\section{Clinical Variables}

Clinical data show that greater number of patients had cardiac surgery ( $80 \%$ and $73.34 \%)$, with chest tube in place for 1 to 3 days (90\% and $83.34 \%)$ with both anterior and pleural drain $(50 \%$ and $73 \%)$, with pleural drain alone (33\% and $20 \%$ ), and with anterior drain alone (16\%\% and $6 \%)$. Majority of the patients $(96.67 \%$ and $90 \%$ ) had no previous experience of chest tubes and had increased severity of pain (63.34\% and $63.34 \%)$ during chest physiotherapy. Most of them had comorbid illness (60\% and $56.67 \%$ ) in the control and the ice pack groups, respectively.

\section{Severity of Pain in the Control and the Ice Pack Group of Patients with Chest Tubes before and after Ice Pack Application}

Majority of the patients in the control group had severe pain in pretest and in posttest (100\% and $100 \%)$, respectively. In the ice pack group, almost everyone had severe pain in pretest (100\%). However, after ice pack application, majority (90\%) of them had mild pain in the ice pack group.

Table 1: Comparison of mean and standard deviation of the severity of pain before and after ice pack application between the control and the ice pack group

\begin{tabular}{|c|c|c|c|c|c|}
\hline \multirow[b]{2}{*}{ Severity pain } & \multicolumn{2}{|c|}{ Control group $(n=30)$} & \multicolumn{2}{|c|}{ Ice pack group $(n=30)$} & \multirow[b]{2}{*}{ t test } \\
\hline & Mean & $S D$ & Mean & $S D$ & \\
\hline \multicolumn{6}{|c|}{ Numerical rating scale } \\
\hline Pretest & 9.13 & 0.61 & 9 & 0.81 & 1.34 \\
\hline Posttest & 7.06 & 0.77 & 1.8 & 1.11 & $35.39^{*}$ \\
\hline \multicolumn{6}{|c|}{ Mc Gill Pain questionnaire } \\
\hline Pretest & 3 & 0.17 & 3 & 0 & 0 \\
\hline Posttest & 2 & 0.51 & 0.1 & 0 & $31.67^{* *}$ \\
\hline
\end{tabular}


Table 2: Association of selected demographic variables and the severity pain before and after ice pack application in the control and the ice pack group of patients with chest tubes

\begin{tabular}{|c|c|c|c|c|}
\hline \multirow[b]{3}{*}{ Demographic variables } & \multicolumn{2}{|c|}{ Control group $(n=30)$} & \multicolumn{2}{|c|}{ Ice pack group $(n=30)$} \\
\hline & \multicolumn{2}{|c|}{ Chisquare } & \multicolumn{2}{|c|}{ Chisquare } \\
\hline & Pretest & Posttest & Pretest & Posttest \\
\hline \multicolumn{5}{|l|}{ Age } \\
\hline$<40$ years & $0.08(\mathrm{df}-1)$ & $0.835(\mathrm{df}-1)$ & $2.08(\mathrm{df}-1)$ & $0.54(\mathrm{df}-1)$ \\
\hline \multicolumn{5}{|l|}{$>40$ years } \\
\hline \multicolumn{5}{|l|}{ Gender } \\
\hline Male & $2.05(\mathrm{df}-1)$ & $0.27(\mathrm{df}-1)$ & $1.67(\mathrm{df}-1)$ & $0.192(\mathrm{df}-1)$ \\
\hline \multicolumn{5}{|l|}{ Female } \\
\hline \multicolumn{5}{|l|}{ Nature of work } \\
\hline Moderate & $0.596(\mathrm{df}-1)$ & $1.07(\mathrm{df}-1)$ & $0.417(\mathrm{df}-1)$ & $0.496(\mathrm{df}-1)$ \\
\hline \multicolumn{5}{|l|}{ Heavy } \\
\hline \multicolumn{5}{|c|}{ History of smoking and alcoholism } \\
\hline Smoking and alcoholism & $0.0003(\mathrm{df}-1)$ & $0.0007(\mathrm{df}-1)$ & $4.80^{*}(\mathrm{df}-1)$ & $1.703(\mathrm{df}-1)$ \\
\hline \multicolumn{5}{|l|}{ Both and none } \\
\hline \multicolumn{5}{|l|}{ Type of diet } \\
\hline Vegetarian & $1.590(\mathrm{df}-1)$ & $1.363(\mathrm{df}-1)$ & $0.017(\mathrm{df}-1)$ & $0.06(\mathrm{df}-1)$ \\
\hline Mixed & & & & \\
\hline
\end{tabular}

Table 3: Association of selected clinical variables and the severity pain before and after ice pack application in the control and the ice pack group of patients with chest tubes

\begin{tabular}{|c|c|c|c|c|}
\hline \multirow[b]{3}{*}{ Clinical variables } & \multicolumn{2}{|c|}{ Control group $(n=30)$} & \multicolumn{2}{|c|}{ Ice pack group $(n=30)$} \\
\hline & \multicolumn{2}{|c|}{ Chi square } & \multicolumn{2}{|c|}{ Chisquare } \\
\hline & Pretest & Posttest & Pretest & Posttest \\
\hline \multicolumn{5}{|l|}{ Diagnosis } \\
\hline Cardiac surgery & $2.08(\mathrm{df}-1)$ & $0(\mathrm{df}-1)$ & $5.48^{*}(\mathrm{df}-1)$ & $1.022(\mathrm{df}-1)$ \\
\hline \multicolumn{5}{|l|}{ Thoracic surgery } \\
\hline \multicolumn{5}{|l|}{ Type of chest drain } \\
\hline Anterior and pleural & $0.68(\mathrm{df}-1)$ & $0.06(\mathrm{df}-1)$ & $2.077(\mathrm{df}-1)$ & $1.022(\mathrm{df}-1)$ \\
\hline \multicolumn{5}{|l|}{ Both } \\
\hline \multicolumn{5}{|l|}{ No. of chest drain } \\
\hline 1 and 2 & $0.004(\mathrm{df}-1)$ & $0.62(d f-1)$ & $0.105(d f-1)$ & $0.238(\mathrm{df}-1)$ \\
\hline \multicolumn{5}{|l|}{3 and 4} \\
\hline \multicolumn{5}{|c|}{ Physical activity that increase pain } \\
\hline Chest physiotherapy & $0.83(\mathrm{df}-1)$ & $2.4(d f-1)$ & $0.33(\mathrm{df}-1)$ & $0.03(\mathrm{df}-1)$ \\
\hline \multicolumn{5}{|c|}{ Ambulation and positioning } \\
\hline \multicolumn{5}{|c|}{ Ambulated with chest tubes } \\
\hline Yes & $0.006(\mathrm{df}-1)$ & $0.14(d f-1)$ & $0.05(d f-1)$ & $0.814(\mathrm{df}-1)$ \\
\hline No & & & & \\
\hline
\end{tabular}

The abovementioned findings are consistent with the study conducted by Ertug and Ulker (2012) to ascertain the efficacy of ice application on the pain during chest tube removal for patients with single pleural chest tube. Of the 140 patients, 70 patients were put in experimental and control groups respectively, in a thoracic hospital in Turkey. The tools used for data collection were demographic profile, health history, and VAS. Ice was applied to patients in the ice pack group prior to chest tube removal. The results revealed that the VAS score was found to be 3.85 in the ice pack group compared to 5.60 in the control group. This statistically significant difference in pain severity with ice application between the 2 groups prior to and after the intervention shows its efficacy. ${ }^{10}$

Demir and Khorshid conducted a single blinded randomized trial to determine the effect of cold application on pain and anxiety in the course of chest tube removal in patients who had undergone cardiac surgery. Ninety patients with chest tube were selected by convenient sampling technique and were put in three 
groups, namely, experimental, placebo, and control groups. Sixty minutes before the removal of chest tube, paracetamol was given intravenously to all the patients. Cold and warm packs covered with gauze dressing were applied to the site around the chest tubes for 20 minutes. Pain intensity, quality, and situational anxiety were assessed. Patients in the ice pack group had decreased pain intensity than the placebo group. The application of cold increased the length of time until analgesics were needed after chest tube removal. Also, cold application reduced patients' intensity of pain due to chest tube removal but did not affect anxiety levels or the type of pain. ${ }^{11}$

\section{Type of Pain Assessed Using Mc Gill Questionnaire in Control and Ice Pack Group of Patients with Chest Tubes before and after Ice Pack Application}

Majority of the patients in the control group had stabbing type of pain (33.34\% and $30 \%)$, most of them sharp pain and burning pain (23.34\% and $23.34 \%$ ) in pretest and posttest, respectively.

Sauls aimed to experiment with ice for pain related to chest drain removal in 50 postoperative cardiac patients. The study concluded that there was a notable change in the severity of pain by the use of ice. The pain described was cramping and gnawing type of pain. The type of pain may differ in par with the drain tube size, patient perception, type, and dose of analgesics that are administered, sedation action, and the ice pack temperature. $^{12}$

\section{Comparison of Mean and Standard Deviation of the Severity of Pain before and after Ice Pack Application between the Control and the Ice Pack Group}

Analysis between posttest scores of pain in the control group by Numerical rating scale chest tube removal and Mc Gill Pain questionnaire $(M=2, S D=0.51)$ and ice pack group by Numerical rating scale $(M=1.8, S D=1.11) M c$ Gill Pain questionnaire $(M=0.1$, $\mathrm{SD}=0$ ) showed a statistically significant difference for ' $t$ ' value of 35.39 (NRS) and 31.67 (Mc Gill Pain questionnaire) at $p$ value $<0.001$ which may be attributed to the ice pack application.

\section{Association of Selected Demographic Variables, Clinical Variables, and the Severity of Pain before and after Ice Pack Application in the Control and the Ice Pack Group of Patients with Chest Tubes.}

It could be observed from this study that there was a significant association between history of smoking and alcoholism at ${ }^{*} p$ value $<0.05$ and the severity of pain.

Among the clinical variables, there was a significant association between those who had undergone cardiac surgeries at * $p$ value $<0.002$ and the severity of pain in ice pack group of patients. Thus, cardiothoracic surgeries play an associative role and pose an impact on pain in chest drain and its removal.

\section{Conclusion}

Although there are various therapies for relieving pain, ice pack therapy can be accredited for its efficacy in relieving pain promptly. Thus, the study concludes that ice pack application can improve patient comfort by relieving pain with no side effects.

\section{References}

1. Sullivan B. Nursing management of patients with chest drain. $\mathrm{Br} \mathrm{J}$ Nurs 2008;17(6):388-393. DOI: 10.12968/bjon.2008.17.6.28906. https:// www.ncbi.nlm.nih.gov/pubmed/18414310.

2. Owen $S$, Gould D. Underwater seal chest drain: patient experience. J Clin Nurs 1997;6(3):215-225. DOI: 10.1111/j.1365-2702.1997.tb00307.x. https://www.ncbi.nlm.nih.gov/pubmed/9188339.

3. Gorji H, Nesamani B, Ayyasi M, Ghafari B, Yazdani J. Comparison of ice pack application and relaxation therapy in pain reduction during chest tube removal following cardiac surgery. N Am J Med Sci 2014;6(1):19-24.PMID24678472 10.4103/1947-2714.125857. https:// www.ncbi.nlm.nih.gov/pubmed/24678472.

4. Casey E, Lane A, Kuriakose D, et al. Bolus remifaentanil for chest drain removal in icu:randomized double blinded clinical trial. Intensive Care Med 2010;36(8):1380-1385. DOI: 10.1007/s00134-010-1836-2. https:// www.ncbi.nlm.nih.gov/pubmed/20237760.

5. Ernst E, Fialka V. Ice freezes pain? A review of the clinical efficay of analgesic cold therapy. J Pain Symptom Manage 1994;9(1):56-59. DOI: 10.1016/0885-3924(94)90150-3.

6. Hsieh LY, Chen YR, Lu MC. Efficacy of cold application on pain during chest tube removal: a randomized Controlled trial. Medicine (Baltimore) 2017;96(46):e8642. DOI: 10.1097/MD.0000000000008642. PMID 29145288 https://www.ncbi.nlm.nih.gov/pubmed/29145288.

7. Payami M, Daryei N, Mowavanasab N, Nowariz E. Effect of cold application in combination with indomethacin suppository on chest tube removal in patients undergoing open heart surgery. Iran J Nurs Midwifery Res 2014;19(1):77-81. PMID 24554964. https://www.ncbi. nlm.nih.gov/pubmed/24554964.

8. Mazolum SR, Teshnizi AM, Kianinejad A, et al. Effect of applying ice bag on pain intensity associated with chest drain removal after cardiac surgery. Horizon Med Sci 2012;18(3):109-114. http://hms.gmu. ac.ir/browse.php?a_id=1270\&sid=1\&slc_lang=en.

9. Improving the quality of care through pain assessment management. In: Wells N, Pasero C, McCaffery M Patient safety and quality: an Evidence based handbook for nurses. https://www.ncbi.nlm.nih. gov/books/NBK2658/.

10. Ertug N, Ulker $\mathrm{S}$. The effect of cold application on pain due to chest tube removal. J Clin Nurs 2012;21(5-6):780. DOl: 10.1111/j.1365-2702.2011.03955.x. https://www.ncbi.nlm.nih.gov/ pubmed/22082021.

11. Demir Y, Khorshid L. The effect of cold application with standard analgesic administration on pain and anxiety during chest drain removal: a single-blinded, randomized, double controlled study. Pain Manag Nurs 2010;11(3):186-196. https://www.ncbi.nlm.nih.gov/ pubmed/20728068.

12. Sauls J. The use of ice for pain associated with chest tube removal. Pain Manag Nurs 2002;3(2):44-52. DOI: 10.1053/jpmn.2002.123017. https://www.researchgate.net/publication/11322477_The_Use_of_ Ice_for_Pain_Associated_with_Chest_Tube_Removal. 